\title{
Influence of Rapid Mould Temperature Variation on the Appearance of Injection-Moulded Parts
}

\author{
Giovanni Lucchetta* - Marco Fiorotto \\ University of Padua, Department of Industrial Engineering, Italy
}

In this work, an innovative technology for the rapid heating and cooling of injection moulds has been developed and used to analyse the effect rapid variations of the mould temperature on the improvement of mouldings' appearance in terms of gloss. The obtained experimental results show that by maintaining an elevated mould surface temperature, the polymer melt is prevented from solidifying prematurely in the filling and packing stage, thereby improving the replication of the mirror-finished cavity surface. Furthermore, the mould cavity heating combined with the rapid cooling of the moulded part significantly contributes to contrasting the development of surface defects, such as weld line marks.

Keywords: injection moulding, rapid heat cycle moulding, gloss

\section{INTRODUCTION}

In recent years, the rapid growth of the computer, communication and consumer electronics industries has driven demand for producing plastic parts with high-quality finishes. The surface gloss of thermoplastic parts is an essential characteristic as it affects the optical behaviour and the aesthetics of the parts [1]. Gloss varies with the refractive index of the polymer, the angle of incidence and the topography of the surface [2].

Previous studies on polymer injection moulding have indicated that gloss improves with increasing mould temperature [3] for some rubber-modified thermoplastics and for pigmented polypropylene [4]. Mould temperature was shown to have a significantly higher influence on gloss than melt temperature, the effect of the latter being negligible for acrylonitrilebutadiene-styrene (ABS) [5]. Increasing the values of the holding time even out the gloss of ABS mouldings after an initial improvement [5], while an increase of packing pressure improves the gloss for the same polymer [6]. Cooling time has a negligible effect on gloss, both for stochastic [7] and geometric micro-structures [8]. Oliveira et al. [9] studied the modifications of the surface morphology and microtopography of injection-moulded ABS parts caused by the processing conditions and they related them with gloss. This work showed that the surface finish and appearance of injection-moulded parts are highly dependent on the process parameters and in particular on the mould temperature.

Moulding gloss can be substantially improved by increasing the cavity surface temperature. However, this solution involves higher manufacturing costs due to the significantly longer cooling time. Therefore, technologies for rapid mould temperature variation, known as rapid heat cycle moulding (RHCM), have been developed especially in the last decade [10]. In this process, a mould is first heated to a pre-set high temperature before melt injection, then kept at the high temperature during filling and packing, and finally cooled to solidify the polymer melt for demoulding. For amorphous polymers, the tool is heated up to a temperature that is $10{ }^{\circ} \mathrm{C}$ higher than the glass transition $\left(T_{g}\right)$. The use of RHCM has come to prominence recently, mainly as a result of a commercial incentive to produce high-gloss mouldings without visible weld lines.

Among all available heat generation technologies, electrical resistive heating is the most widely used mechanism for rapid mould heating. It is usually accomplished by passing direct or alternating current in cartridge heaters or in a thin electrical conductive layer [11]. The first solution is robust but energy inefficient and slow while the latter is rapid but the thin conductive layer wears out extremely quickly.

Alternatively, high-frequency electrical current can be generated at the surface of a large mould mass by the skin effect from a high-frequency electromagnetic field. Two useful technical approaches for implementing this skin effect are induction heating [12] and proximity heating [13]. Induction heating has been effectively used to improve the appearance of moulding surfaces [14] and to assist the micro-injection of high aspect ratio microfeatures [15]. This technology was also employed in compression moulding [16]. Infrared radiation has also been applied for heating the cavity surface [17] and [18]. However, induction, proximity and infrared heating require high initial investments in equipment.

Another solution to thermally cycle the mould temperature is by alternating two heating and cooling fluids in the mould [19]. These fluids impose a 
convective heat flux at the fluid-solid interface. The hot fluid may be circulated inside the mould or directly introduced to the mould surface from the cavity.

Efficient heating can be achieved using either superheated steam [20] or pressurized hot water circulating in conformal cooling channels [21] or ball bearing-filled slots located in proximity of the cavity wall and connected in a series with the cooling channels [22]. Both the conformal channels and ball bearing filling allow rapid and uniform heating of the cavity and provide mechanical support to contrast high injection pressures. However, conformal cooling channels are expensive to produce while ball bearingfilled slots can be realized only for parts with plane geometry.

In this work, an innovative RHCM system has been developed to overcome the limitations of the available technologies [23] and [24], and has been used to analyse the effect of rapid variation of the mould temperature on moulding gloss. The proposed solution is based on the ball filling technology but replaces ball bearings with inserts made of opencell aluminium foam, which possesses high strength for structural applications, and elevated convection coefficients for heat transfer [25].

\section{MOULD DESIGN}

The heating and cooling system geometry is of considerable importance because it affects the heating/ cooling efficiency and temperature uniformity. In this work, a new mould, based on the use of open-cell aluminium foam, was designed. A $64 \times 24 \times 2 \mathrm{~mm}$ cover plate was chosen as a test case to study the efficiency of the proposed solution (Fig. 1).

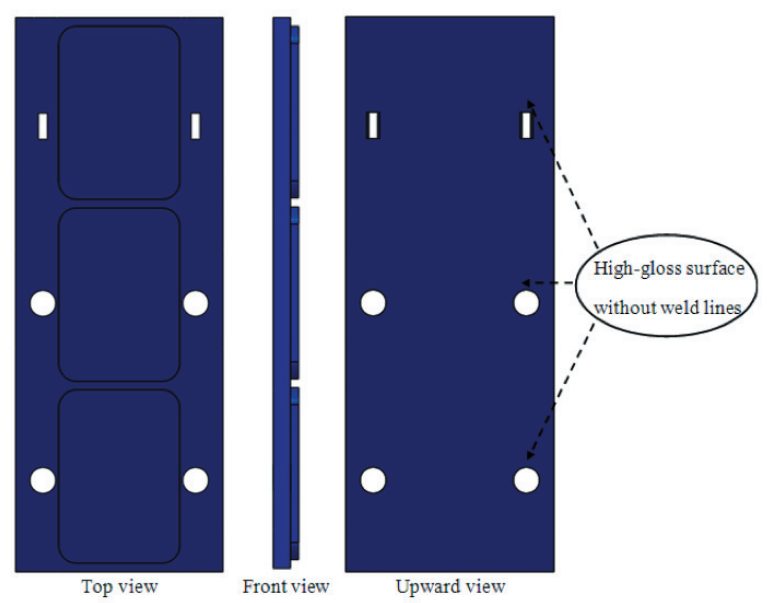

Fig. 1. Cover plate used as a case study
Fig. 2 is a schematic representation of the new RHCM mould. A K-type thermocouple was placed $1 \mathrm{~mm}$ from the cavity surface to detect the mould temperature profile during the moulding cycle. The layout of the heating/cooling system in the cavity insert is reported in Fig. 3.

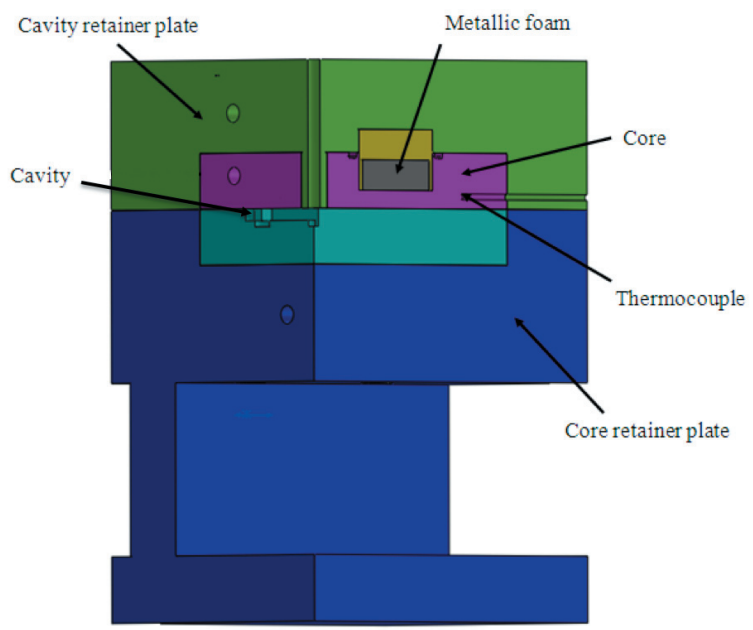

Fig. 2. Model of the RHCM mould

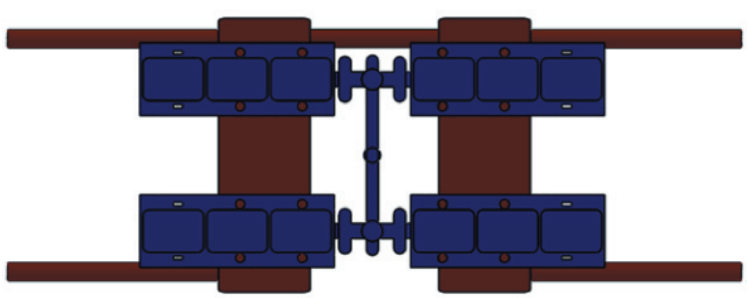

Fig. 3. Layout of the heating/cooling systems in the cavity insert

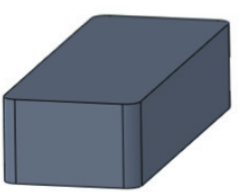

a)

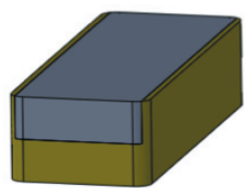

b)

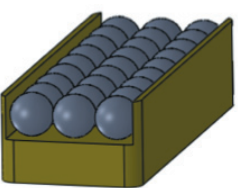

c)
Fig. 4. Layout of the different RHCM systems: a) $90 \times 33 \times 20$ $\mathrm{mm}$ aluminium foam, b) $90 \times 30 \times 10 \mathrm{~mm}$ aluminium foam and c) $90 \times 30 \times 10$ ball filling

Two slots were realized at a distance of $6 \mathrm{~mm}$ from the cavity surface and were filled with three different inserts (Fig. 4). First, two inserts of open cell aluminium foam of $90 \times 33 \times 20 \mathrm{~mm}$ were used. The metal foam, supplied by ERG Materials and Aerospace Corporation, has 5 pores/cm (Fig. 5). In the second arrangement, a $90 \times 30 \times 10 \mathrm{~mm}$ insert of aluminium foam was used. For comparison, the cover plate was produced replacing the aluminium foam 
with a ball bearing filling. The balls have a diameter of $10 \mathrm{~mm}$ (Fig. 6).

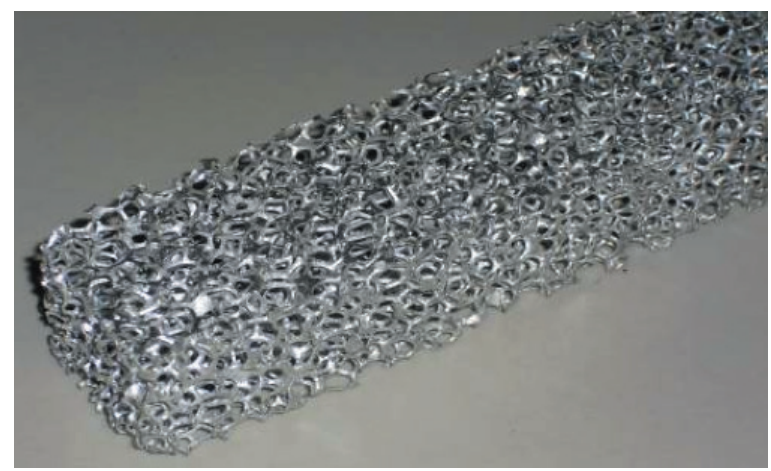

Fig. 5. Insert made of open cell aluminium foam

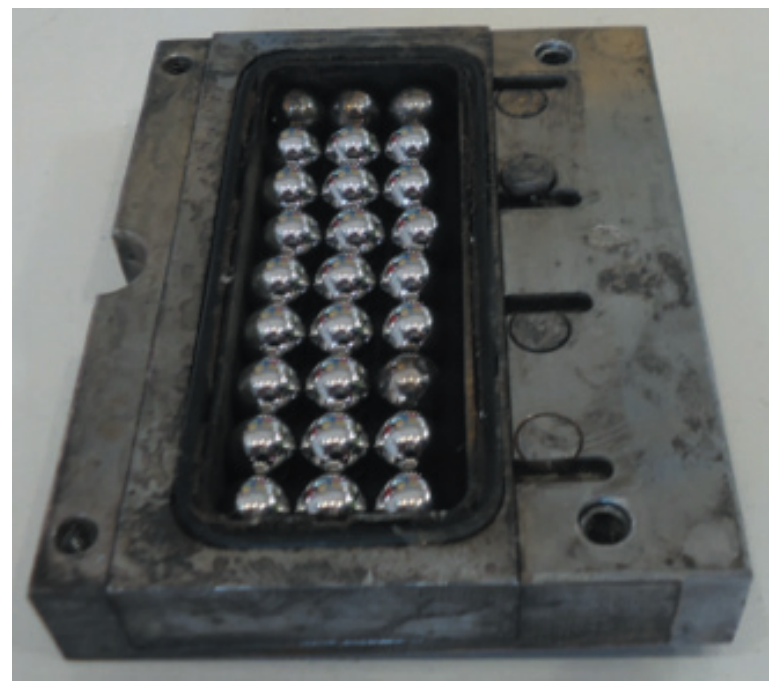

Fig. 6. Mould slot filled with bearing balls

\section{EXPERIMENTAL METHOD}

The polymer used in this study is an ABS (BASF Terluran KR 2922). The material was characterized by means of a differential scanning calorimeter (TA Instruments Q200). The measured glass transition temperature is $95.35^{\circ} \mathrm{C}$.

The injection speed and the melt temperature were set to the highest limits of the moulding window in order to decrease the viscosity of the polymer during the injection phase. The experimental tests were conducted on a $1100 \mathrm{kN}$ injection moulding machine (Wittmann-Battenfeld HM110). Before the injection phase, the mould was heated with water circulating at a temperature of $140{ }^{\circ} \mathrm{C}$ until the temperature in correspondence of the thermocouple position reached $100{ }^{\circ} \mathrm{C}$. After the packing phase, it was cooled with water at $30^{\circ} \mathrm{C}$. A high-performance thermal unit equipped with two conditioning systems and a valve exchange unit (Wittmann-Battenfeld Tempro plus C160 Vario) was used to rapidly vary the cavity surface temperature. The valve exchange device alternates the heating water and the cooling water into the channel system by switching the status of the corresponding control valves. When the mould is still open, the hot water flows into the channel by opening the valve. The energy transferred from the hot water to the mould plate heats the cavity surface. The velocity of the cooling water must be high enough to maintain the turbulent flow for cooling the mould. When the cavity surface is heated to a high temperature, the mould is closed in preparation for the filling process. When the heating process is finished, the temperature at the cavity surface reaches the target value for assistance in the filling and packing of the melt. At this time, the valve control is switched to the cold water flowing into the channels, and the cooling process begins.

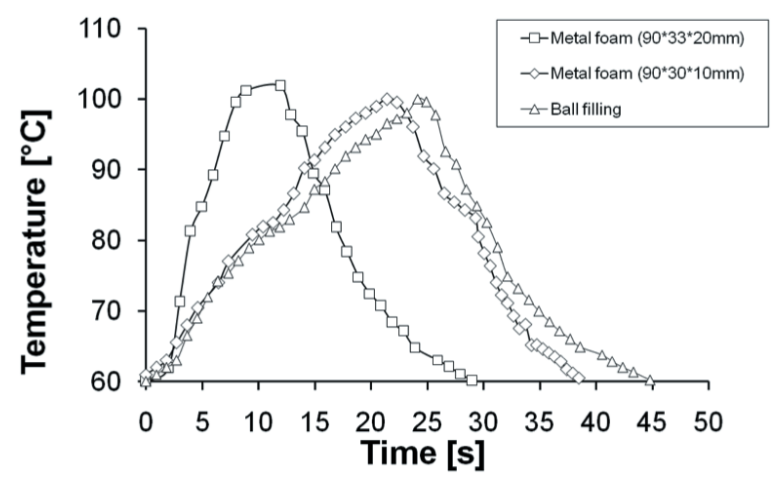

Fig. 7. Comparison of temperature profiles relevant to the different heating/cooling systems

As shown in Fig. 7, the first technology, based on the single use of metal foam, allows drastic reductions of the heating and cooling times, by about 7 and $16 \mathrm{~s}$, respectively. Table 1 reports the heating and cooling rate values for the three tested RHCM systems.

Table 1. Heating and cooling rate values for the three tested $\mathrm{RHCM}$ systems

\begin{tabular}{lcc}
\hline & Heating rate $\left[{ }^{\circ} \mathrm{C} / \mathrm{s}\right]$ & Cooling rate $\left[{ }^{\circ} \mathrm{C} / \mathrm{s}\right]$ \\
\hline $20 \mathrm{~mm}$ foam & 5.0 & 2.4 \\
\hline $10 \mathrm{~mm}$ foam & 1.9 & 2.4 \\
\hline $10 \mathrm{~mm}$ ball bearing filling & 1.7 & 2.0 \\
\hline
\end{tabular}

For RHCM, the required heating and cooling time of the mould mostly depends on the mass of the cavity/core to be heated and cooled. A mould with a low thermal mass exhibits a low thermal inertia and can be rapidly heated and cooled. With an increase of 
the thickness of the metal foam inserts, the volume of the material being heated is reduced with a consistent improvement in cycle time.

\section{EFFECT OF RHCM ON THE PRODUCT APPEARANCE}

All heating/cooling systems allow producing highgloss parts without visible weld lines, which should be located near each hole (Fig. 3) of the cover frame shown in Fig. 8 if this part was moulded using a conventional injection moulding process. This is due to the fact that all of the tested systems were able to reach mould temperature values higher than the glass transition temperature of the ABS used in the experiments.

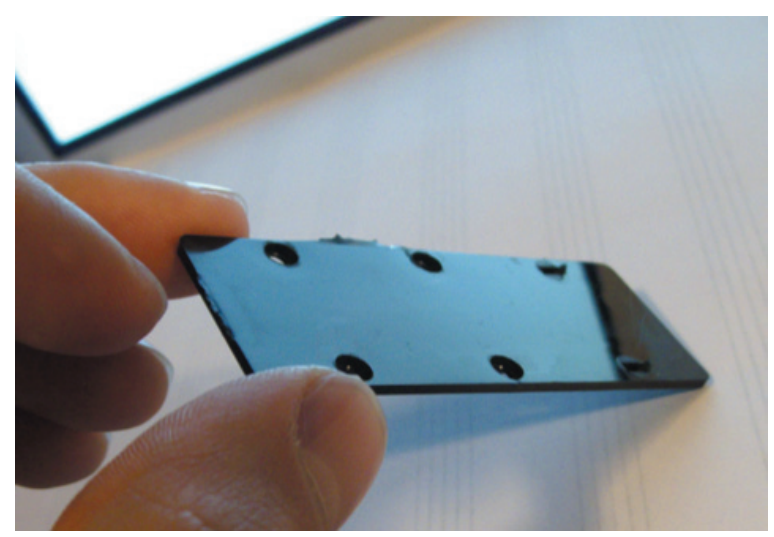

Fig. 8. High quality cover plate

Only the cover plates produced using the new RHCM technology with metal foam of $90 \times 33 \times 20$ $\mathrm{mm}$ were chosen for the gloss analysis. Surface gloss is a subjective impression created by the light flux reflected by a part. In industrial practice, surface gloss is often expressed in relation to the reflection from an ideal polished black surface in the specular direction [26] and [27]. Gloss is measured with a glossmeter, and the results are expressed in gloss units (GU), which are calculated as the reflectometer reading for the surface concerned calibrated with respect to that of a standardized black glass plate with a known refractive index. Spectrophotometers operating in the reflection mode and diffractive optical sensors have also been used to study the gloss differences of injection-moulded plastic products.

In this study, the effect of the rapid variation of the mould temperature on surface gloss was analysed using a UV/VIS spectrophotometer (Jasco, V-570) operating in reflection mode. The total reflectance at point $\mathrm{A}$ was measured (Fig. 9). The angle of incidence of the spectrophotometer is fixed to $8^{\circ}$ to the perpendicular direction. The diameter of the probe beam of the spectrometer was adjusted to $3 \mathrm{~mm}$. The diffuse reflectance was measured by trapping and removing the specular component. The specular reflectance was calculated by subtracting the diffuse reflectance from the total reflectance.

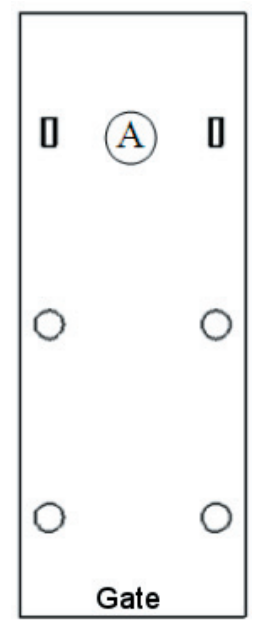

Fig. 9. Measurement location

The process variables that were analysed in the experimental design were the mould temperature values measured by the thermocouple at the injection $\left(T_{1}\right)$ and the ejection $\left(T_{2}\right)$ phases. A simple onefactor-at-a-time design was used, according to values reported in Table 2. Each experiment was replicated four times.

Table 2. One-factor-at-a-time experimental design

\begin{tabular}{ccc}
\hline Experiment & $T_{1}\left[{ }^{\circ} \mathrm{C}\right]$ & $T_{2}\left[{ }^{\circ} \mathrm{C}\right]$ \\
\hline $\mathrm{A}$ & 60 & 60 \\
\hline $\mathrm{B}$ & 80 & 60 \\
\hline $\mathrm{C}$ & 100 & 60 \\
\hline $\mathrm{D}$ & 100 & 50 \\
\hline $\mathrm{E}$ & 100 & 70
\end{tabular}

Keeping heating and cooling water temperatures at constant values of 140 and $30^{\circ} \mathrm{C}$, respectively, $T_{1}$ and $T_{2}$ were set by varying heating and cooling times according to the temperature profiles shown in Fig. 7.

Fig. 10 shows the comparison of average reflectance results (as mean reflectance values per treatment). A one-way ANOVA conducted on the first three experiments revealed that the mould temperature at injection $\left(T_{1}\right)$ has a significant influence on the reflectance (Fig. 11). The results show a significant difference in surface gloss between the conventional injection moulding process $\left(T_{1}\right.$ of $60{ }^{\circ} \mathrm{C}$, experiment 
A) and RHCM with mould temperature higher than $T_{g}$ (experiment C). Such high-glossy surface can be explained by the fact that only at temperatures higher than $T_{g}$ can the mirror-finished surface of the cavity be entirely replicated onto the moulding surface, because the injected polymer melt cannot solidify at first mould contact.

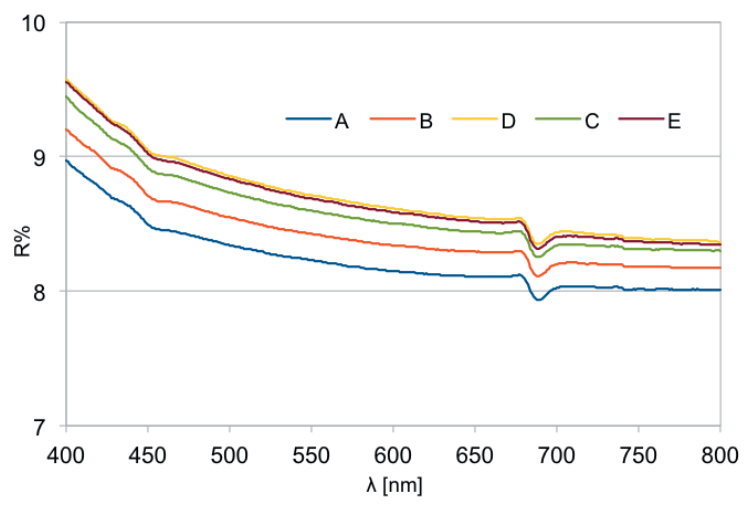

Fig. 10. Specular reflectance from the test location

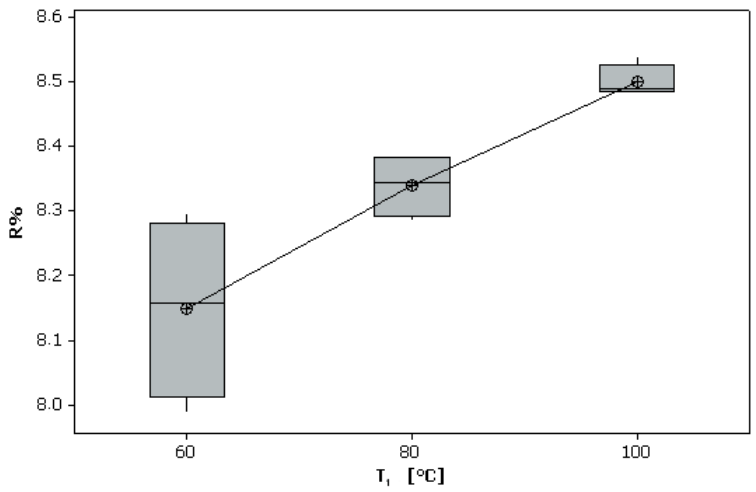

Fig. 11. Influence of the mould temperature at injection $\left(T_{1}\right)$ on reflectance

A one-way ANOVA conducted on the last three experiments revealed that the mould temperature at ejection $\left(T_{2}\right)$ has a negligible influence on the reflectance. This setting is, however, essential for keeping cycle time values low.

\section{CONCLUSIONS}

In this work, an innovative RHCM system has been developed and used to analyse the effect of the rapid variation of the mould temperature on appearance of injection-moulded parts. The proposed solution is based on the ball filling technology (BFMOLDTM) but replaces ball bearings with inserts made of opencell aluminium foam, which allow increasing the heat exchange surface as compared to the traditional cooling channels. A prototype mould was designed and realized. Two inserts of open-cell aluminium foam were placed just under the cavity surface and were integrated in the conditioning system of the mould. The metallic foam allows the flowing of a fluid at a controlled temperature and generates a cavity structure that favours an evenly spread tempering system immediately below the mould surface.

The temperature profile near the cavity surface was detected by a thermocouple and was compared with experimental values measured in the same reference point, using thinner metallic foam inserts and ball bearing filling. The comparison between the ball bearing filling technology and the RHCM system with metal foams shows that the solution proposed in this work allows an improvement in the cycle time of about $16 \mathrm{~s}$. Furthermore, the mould cavity heating combined with the rapid cooling of the moulded part contributed to eliminating the development of visible weld lines and to producing high-gloss parts.

The innovative RHCM system was used to analyse the effect of rapid variations of the mould temperature on the specular reflectance of the moulding surface. The rapid heating and cooling to the mould surface leads to a significant improvement in surface gloss when heating the mould up to a temperature higher than $T_{g}$. This is mainly because the high cavity surface temperature can prevent the melt from freezing prematurely in the filling and packing stage and improve the replication of the mirrorfinished cavity surface, resulting in superior aesthetics (no visible weld line) and higher gloss.

\section{REFERENCES}

[1] Berger, G.R, Friesenbichler, W., Teichert, C. (2010). Replication of stochastic and geometric micro structures: Effects on functionality and visual appearance. 26th Annual Meeting of the Polymer Processing Society, Banff.

[2] Ignell, S., Kleist, U., Rigdahl, M. (2009). Visual perception and measurements of texture and gloss of injection-molded plastics. Polymer Engineering and Science, vol. 49, no. 2, p. 344-353, DOI:10.1002/ pen.21279.

[3] Dawkins, E., Engelmann, P., Horton, K. (1998). Color and Gloss - The Connection to Process Conditions. Journal of Injection Molding Technology, vol. 2, no. 1, p. 1-7.

[4] Pisciotti, F., Boldizar, A., Rigdahl, M., Arino, I. (2005). Effects of injection-molding conditions on the gloss and color of pigmented polypropylene. Polymer Engineering and Science, vol. 45, no. 12, p. 1557-1567, DOI:10.1002/ pen.20358. 
[5] Koppi, K.A., Ceraso, J.M., Cleven, J.A., Salamon, B.A. (2002). Gloss modeling of injection molded rubbermodified styrenic polymers. SPE ANTEC Technical Papers, vol. 48, p. 184-188.

[6] Edwards, S.A., Choudhury, N.R. (2004). Variations in surface gloss on rubber-modified thermoplastics: relation to morphological and rheological behavior. Polymer Engineering and Science, vol. 44, no. 1, p. 96112, DOI:10.1002/pen.20009.

[7] Schauf, D. (1988). Application Technology Information (ATI) 584e: Reproducing Textures from the Cavity Surface to the Surface of the Thermoplastic Moulding. Bayer Material Science AG, Leverkusen.

[8] Berger, G.R., Gruber, D.P., Friesenbichler, W., Teichert, C., Burgsteiner M. (2011). Replication of stochastic and geometric micro structures: aspects of visual appearance. International Polymer Processing, vol. 26, no. 3, p. 313322, DOI:10.3139/217.2451.

[9] Oliveira, M.J., Brito, A.M., Costa, M.C., Costa, M.F. (2006). Gloss and surface topography of ABS: a study on the influence of the injection molding parameters. Polymer Engineering and Science, vol. 46, no. 10, p. 1394-1401, DOI:10.1002/pen.20607.

[10] Guilong, W., Guoqun, Z., Huiping, L., Yanjin, G. (2010). Analysis of thermal cycling efficiency and optimal design of heating/cooling systems for rapid heat cycle injection molding process. Material and Design, vol. 31, no.7, p. 3426-3441, DOI:10.1016/j.matdes.2010.01.042.

[11] Yao, D., Kim, B.Y. (2002). Development of rapid heating and cooling systems for injection molding applications. Polymer Engineering and Science, vol. 42, no. 12, p. 2471-2481, DOI:10.1002/pen.11133.

[12] Chen, S.C., Jong, W.R, Chang, J.A., Chang, Y.J. (2006). Dynamic mold surface temperature control using induction and heater heating combined with coolant cooling. International Polymer Processing, vol. 21, no. 5, p. 457-463.

[13] Yao, D., Kimberling, T.E., Kim, B. (2006). Highfrequency proximity heating for injection molding applications. Polymer Engineering and Science, vol. 46, no. 7, p. 938-945, DOI:10.1002/pen.20548.

[14] Chen, S.C., Jong, W.R., Chang, J.A., (2006). Dynamic mold Surface Temperature Control Using Induction Heating and its Effects on the Surface Appearance of Weld Line. Journal of Applied Polymer Science, vol. 101, no. 2, p. 1174-1180, DOI:10.1002/app.24070.

[15] Chen, S.C., Jong, W.R., Chang, Y.J., Chang, J.A., Cin, J.C. (2006). Rapid mold temperature variation for assisting micro injection of high aspect ratio microfeature parts using induction heating technology. Journal of Micromechanics and Microengineering, vol. 16, no. 9, p. 1783-1791, DOI:10.1088/0960-1317/16/9/005.
[16] Miller, K., Ramani, K. (1998). Analysis of an inductively heated compression molding process. Advances in Polymer Technology, vol. 17, no. 3, p. 251-257, DOI:10.1002/(SICI)1098-2329(199823)17:3<251::AIDADV5>3.0.CO;2-R.

[17] Yu, M.C., Young, W.B., Hsu, P.M. (2007). Micro injection molding with the infrared assisted heating system. Materials Science and Engineering: A, vol. 460, no. 461, p. 288-295, DOI:10.1016/j.msea.2007.02.036.

[18] Berger, G.R., Roock, S., Gießauf, J., Gruber, D.P., Friesenbichler, W., Steinbichler, G. (2011). Improving the polymer surface quality by infrared radiation driven dynamic mold temperature control. 27th Annual Conference of Polymer Processing Society, Marrakech.

[19] Fu, G., Loh, N.H., Tor, S.B., Tay, B.Y., Murakoshi, Y., Maeda, R. (2005). A Variotherm mold for micro metal injection molding. Microsystem Technologies, vol. 11, no. 12, p. 1267-1271, DOI:10.1007/s00542-005-0605-6.

[20] Zhao, G.-Q., Wang, G.-L., Li, H.-P., Guan, Y-J. (2009). Research and application of rapid heating cycle molding technology. Journal of Plasticity Engineering, vol. 16, no. 1, p. 190-195

[21] Jeng, M.-C., Chen, S.-C., Minh, P.S, Chang, J.A., Chung, C.-S. (2010). Rapid mold temperature control in injection molding by using steam heating. International Communications in Heat and Mass Transfer, vol. 37, no. 9, p. 1295-1304, DOI:10.1016/j. icheatmasstransfer.2010.07.012.

[22] Bariani, P.F., Lucchetta, G., Fiorotto, M. (2011). System for rapid heating and cooling of moulds for polymer materials (Sistema di riscaldamento e raffreddamento rapido di stampi per materiali polimerici). Italian Patent Application PD2011A000117, Italian Patent and Trademark Office, Padova.

[23] Lucchetta, G., Fiorotto, M., Bariani, P.F. (2012). Influence of rapid mold temperature variation on surface topography replication and appearance of injection-molded parts. CIRP Annals - Manufacturing Technology, vol. 61, no. 1, p. 539-542, DOI:10.1016/j. cirp.2012.03.091.

[24] Ozmat, B., Leyda, B., Benson, B. (2004). Thermal applications of open-cell metal foams. Materials and Manufacturing Processes, vol. 19, no. 5, p. 839-862, DOI:10.1081/AMP-200030568.

[25] ASTM Standard D2457 (2008). Standard Test Method for Specular Gloss of Plastic Films and Solid Plastics. ASTM International, West Conshohocken.

[26] ASTM Standard D523 (2008). Standard Test Method for Specular Gloss, ASTM International, West Conshohocken. 